\title{
Articulation of Quality Teaching: A Comparative Study
}

\author{
Mohammad Sakarneh \\ Department of Special Education, Princess Rahma University College, Al-Balqa' Applied University, Al-Salt, Jordan
}

\author{
Received: November 7, 2014 Accepted: November 19, 2014 Online Published: December 5, 2014 \\ doi:10.11114/jets.v3i1.579 \\ URL: http://dx.doi.org/10.11114/jets.v3i1.579
}

\begin{abstract}
The aim of this study is to describe and then contrast the New South Wales Department of Education and Training's model of quality teaching with the Jordanian Ministry of Education's conception of quality teaching, looking particularly at potential differences in interpretation. A content analysis methodology was used. Each perspective has been presented. Comparison and contrast has been made to highlight the similarities and differences between the two perspectives. The results showed that the two perspectives have a constructivist approach orientation. Quality teaching in the two perspectives is a process where the teaching and learning process should be built on the basis of constructing knowledge. In this process the teacher is the guide and facilitator and the students are the constructers of their own knowledge.
\end{abstract}

Keywords: teacher, students, quality teaching, New South Wales quality teaching model, Jordanian Ministry of Education

\section{Introduction}

The concept of quality teaching has been a core issue debated in educational circles both in Jordan and elsewhere. The debate about the quality of teaching and teachers at the micro-level and about the quality of education at the macro-level is the result of an education reform movement in part propagated by international agencies (Berkeley, 1991; Carr, 1989; Hargreaves, 1996); it has been dominant not only in Jordan but also in many other countries.

The education reform movement includes a call from policymakers both for public education to produce citizens able to meet future social and economic demands and for schools to act as social stabilizers (Bascia \& Hargreaves, 2000; Carr, 1989; Corrales, 1999; Crebbin, 2004; Hargreaves, 2003). As a result, politicians have looked to schools and teachers to remedy social and economic problems. It is remarkable that in most nations undertaking this type of micro-reform any perceived failures in the social, economic or political arenas sees blame sheeted home to schools and teachers. Perhaps more pertinently for the situation in the volatile Middle East, if a nation loses a war, sees its economy collapse, or sees unemployment and/or social problems increase, then the school system is held responsible (Massaad et al., 1999). When other agencies and strategies have failed to solve pressing economic and social issues, then the education system is considered the last resort (Hargreaves, 1994, 2003). In other words, responsibility rests on public education to be the savior of society and the economy. Consequently, the education system has experienced changes in its areas of curriculum, teaching practices, teacher education and the participation of stakeholders (Alshurfat, 2003).

Since the Jordanian Ministry of Education (MOE) is a legislative body of educational reform then it is necessarily to provide school stakeholders with blueprint for quality teaching and learning if they (MOE) want their vision to be implemented. School stakeholders cannot guess what is in the MEO back mind. The relationships between both parties are supposed to be built on trust and transparency as it has been addressed in some literature (Dewey, 1916; Organisation for Economic Cooperation and Development, 1994).

If any education reform is to be successful, the dimensions of quality teaching should be included, taught, trained and implemented to meet the aims of that reform. In the experience of Jordanian education reform, these elements are ambiguous; desired teaching practices neither explained clearly nor adequately. To prevent this reform from failing, a tested and developed model of quality teaching practices based on and solidly grounded in theoretical and empirical platforms, such as the NSWQT Model (NSW Department of Education and Training, 2003c), needs to be provided. However, before considering an external and foreign model, it was necessary to examine the two frameworks (the NSWQT Model and the MOE Framework) to understand the way in which the two frameworks articulate the concept of quality teaching. There may be questions about the applicability of a model developed in countries that are quite different from Jordan as a developing country, with differences in religion, language, customs, culture and social 
structure. That many non-Western countries look to the West for some leadership in terms of education practices is not necessarily a mark of inferiority; the Jordanian Government has done so after it has assessed its own needs, one of which is to move towards providing quality education. It is recognized that it is important to understand what makes for quality teaching and learning in primary schools. Furthermore, it is not satisfactory simply to assume that theories apply across all contexts; it is important to explore the differences and similarities of the two models as they developed in different contexts. In part, since reformers have given some recognition to a constructivist approach being appropriate for developing the education systems' potential, there have been calls for research into quality teaching in its context. This study is a response to these demands as it compares and contrasts two frameworks of quality teaching.

\subsection{Objectives}

This study aimed to compare and contrast the NSW Quality Teaching Model and the Jordanian MOE's framework of quality teaching. In other words the study designed to explore the similarities and differences between the two frameworks in terms of their articulation of the concept of quality teaching to reach a conclusion of their understanding of quality teaching. To achieve that; document analysis technique was used as the two models extracted in the form of documents.

\subsection{Reasons for the Selection of the NSW Model for Comparison}

The selection of this model was not random. First, the model was selected because it was developed using 'empirical and theoretical' and longitudinal studies conducted in the USA and Australia that show a strong correlation between quality teaching practices and student achievement (Newmann et al., 1996; Education Queensland, 2001; NSW Department of Education, 2003, p.3). Second, the model can be applied across all school grades from pre-school to high school and for all school subjects (NSW Department of Education and Training, 2003c). Third, this model was developed to help the NSW Department of Education and Training reach the National Goals for Schooling in the Twenty-first Century, known as the Adelaide Declaration (1999). In particular, the model deals with the implications of the declaration in terms of 'social justice and equity', which are meant to undergird other factors that increase students' outcomes (NSW Department of Education and Training, 2003c, p.5). The model shares considerable overlap with the vision of the Jordanian MOE, which, in parallel with ministries in Australia, is to reform education by constructing a sustainable educational system capable of meeting the next millennium's demands and needs in terms of producing skilled and knowledgeable generations (Ministry of Education, 2002). Finally, the model is comprehensive, covering most elements of quality teaching. By reviewing the literature, and conceptualizing and reporting on quality teaching and learning, it was clear to this researcher that the model largely covers the concepts of quality teaching built from a constructivist perspective (Borich, 2000; Brophy \& Good, 1986; Cohen \& Barnes, 1993a; Newmann \& Associates, 1996; Good \& Brophy, 2000; Hughes, 1988; Killen, 2003; Lawton, 1988; McLaughlin \& Talbert, 1993; Newmann et al., 1996; NSW Department of Education, 2003; Shulman, 1987; Williams, 1988). This is the common and desired approach to teaching and learning in the current global education reform movement.

\section{Literature Review}

The world 'quality' has engendered controversy, debate, and interpretation of the illusion of the meaning. However, 'quality', as an adjective, means something that is 'good' or 'excellent' and it can refer to 'a trait or attribute' (Organisation for Economic Cooperation and Development, 1989, p. 27-28). As an extension to this, Downey, Frase and Peters (1994), define quality as 'meeting, exceeding, and delighting customers' needs and expectations with the recognition that these needs and desires will change over time' ( p.8). Despite the prevalence of this concept in education, the meaning of 'quality' remains unclear and no definition can cover it completely. In other places, quality teaching has been defined carefully and understood as being context-dependent and affected by various exogenous factors. Crebbin (2004) transformed the field of debate over the term by focusing on the context of quality teaching: 'In presenting a variety of potential meanings, I am arguing that any definition or practice is not free from the social, cultural, historic, and power contexts in which they have been formed'(p.80). In any case, quality teaching has to be measured and defined on the basis of the quality of learning. Fenstermacher \& Richardson (2005) went to say 'When teaching in the task sense is done well, we called it good teaching. When teaching results in learning, we called it successful teaching, when teaching is both successful and good, we can speak of quality teaching' (Fenstermacher \& Richardson, 2005, p.192). Hence, the meaning of quality generally and quality teaching specifically comes from different backgrounds. These perspectives and backgrounds use the phrase in different ways so that it can serve the contexts where it is supposed function.

Quality teaching does not occur in a vacuum. It occurs in a physical space and this cannot be removed entirely from the related contexts. The whole education system contributes to the teaching - learning process and, if one section or part of the education system is isolated from the other parts, then students' achievements may be affected. With this understanding, Wang and Walberg (1991) reviewed the professional literature and surveyed experts in instruction and 
learning to develop an understanding of the variables that influence learning. Their analysis of variables categories for effective learning environments showed that variables linked to the program design possessed the greatest importance, followed by the context outside of the school, then classroom climate and instruction, and then variables linked to the students. Variables linked to the school and district or state ranked as the least important overall. In the mentioned study, the variables relating to the classroom and teaching still have a high rank or influence in the quality of the learning environment.

Some researchers highlight further factors that may influence the teaching-learning process, including school reform, community dynamics, teacher attitudes, curriculum, school location, and student abilities and socio-economic backgrounds (Maxwell \& Ninnes, 2000b; Paterson, 2000). Quality teaching operates within a complex teaching and learning context that can influence it in different ways. Quality teachers by themselves cannot work effectively and productively unless they are located in a supportive environment.

To meet the new orientation toward quality in teaching measured in a constructivist way, the teaching and learning process has to move seriously towards the practical aspects of quality teaching. According to the most celebrated recent research in this arena, the elements or aspects of quality teaching can be clustered into three main dimensions: 1) the intellectual work of the teacher and students; 2) the quality of the teaching and learning environment and its physical, psychological and social elements; and 3) the relevance to, or connectedness with, real life of the acquired knowledge (Borich, 2000; Bruner, 1966; Cohen \& Barnes, 1993a, 1993b; Dewey, 1916; Driscoll, 2005; Glasser, 1990; Groundwater-Smith, Ewing, \& Cornu, 2003; Killen, 2003; McLaughlin \& Talbert, 1993; Murphy, Delli, \& Edwards, 2004; Newmann, Marks, \& Gamoran, 1996; NSW Department of Education, 2003; Shulman, 1987; Talbert \& McLaughlin, 1993).

A close analysis of the dimensions and their elements found in the NSWQT Model and the Jordanian Ministry of Education's framework reveals that they were derived from a variety of theoretical perspectives in education. For instance, the dimension of intellectual quality was built on the model of Bloom's taxonomy in teaching and learning (Bloom, 1956), while the element of higher order thinking owes much to Newmann's studies in the social studies teaching and learning context (Newmann, 1991; Newmann \& Associates, 1996) and other researchers' work Anyon (1981); Berlak\&Berlak (1981); Bernstein (1971a, 1971b, 1973); Castells (2000); Cazden (1992); Connell (1993); Cope \&Kalantzis (1995); Darling-Hammond \&Youngs (2002); Freebody, Ludwig, \& Gunn (1995); Newman, Griffin, \& Cole (1990); Westage \& Edwards (1986).

The dimension of quality learning environment and its elements reflect ideas and concerns of the research by Anderson \& Burns (1989); Anderson (1994); Barr \& Dreeben (1983); Beane (1993); Bernstein (1971a, 1971b, 1990); Biggs (1991); Bredekamp \& Rosegrant (1995); Brophy \& Good (1986); Cope \& Kalantzis (1995); Darling-Hammond (1997); Darling-Hammond \& Youngs (2002); Dewey (1916); Doyle (1992); Ginott (1971); Glasser (1986, 1990); Groundwater-Smith et al. (1998); Hooks (1994); Lemke (1990); Newmann (1989); Newmann \& Associates (1996); Oakes et al. (1992); Thomas et al. (1998); Willms (2000). In general, it can be said that their research about quality learning environments showed the need for positive, comfortable, fair-minded and productive interactions between teachers and students, both in the classroom and in the school-community more generally.

The dimension of significance has deep roots in the way pedagogy for 'meaningful' learning has been conceptualized: that pedagogy should connect with what students have learnt from 'real life'. It also has been connected to the idea that students construct new knowledge on the basis of, and in connection with, their existing knowledge. This then means that such pedagogy needs to take into consideration the social and cultural diversity at teaching and learning sites. This concept originates in constructivist theory, which asks teachers to elicit students' prior knowledge and experiences to aid the construction of new knowledge on this basis and to connect this knowledge with the students' lives outside the classroom. The elements of this dimension are found collectively in the literature of Bruner (1960, 1966); Christie (1985); Cope \& Kalantzis (1995); Darling-Hammond (1997); Dewey (1956); Egan (1988, 1997); Hymes (1996); Luke (1988); Newmann \& Associates (1996); Thomas et al. (1998) and others mentioned previously.

\section{Method}

The aim of this study was to describe and then contrast the NSW Department of Education and Training's model of quality teaching with the Jordanian MOE's conception of quality teaching, looking particularly at potential differences in interpretation. Using a content analysis methodology, this investigation attempted to answer three questions: How is quality teaching described officially in Jordan? How is quality teaching described officially in NSWQT Model? And what are the areas of similarities and differences?

Official and published documents from the Jordanian MOE and the NSW department of Education were collected and examined. These documents are a fertile ground base to develop the national education strategy in Jordan, and a reference framework for wording the general education plan and sub-plans which are being prepared by the Ministry. 
Therefore, these documents are meant to be a valuable reference for researchers. The NSWQT Model's documents allowed the researcher to understand this model and its roots.

In this investigation, the researcher had to explore the description of quality teaching according to the perspectives of the Jordanian MOE and the NSWQT Model. However, in qualitative paradigm, there is no common formula or recipe for data analysis, each researcher analyzing their data in a unique pattern (Patton, 2002). The researcher treated the documents as a whole body of text. The documents were analyzed in this way because there were few documents and so the researcher had to read and analyze these documents thoroughly. The documents are reliable and reviewed as they are official documents. The documents from Jordan were in English and Arabic and were ad hoc; in analyzing such documents the obvious document analysis techniques, such as electronic or computer programs, were very difficult to apply. The researcher, therefore, treated these documents as texts together and analyzed them by developing a category system. The first aspect to the analysis was the search for the dimensions of quality teaching. The researcher then considered the newly merged patterns, themes, and categories. Documents were analyzed to identify recurring themes, 'developing concepts, and developing a story line' (Anderson \& Burns, 1989, p.201). The meaning of the words, sentences or even paragraphs were coded. Codes here 'are tags or labels for assigning units of meaning to the descriptive or inferential information. Codes usually are attached to "chunks" of varying size - words, phrases, sentences, or whole paragraphs, connected or unconnected to a specific setting' (Miles \& Huberman, 1994, p.56). These codes were essential to organize the amount of information derived from the preceding data techniques and sort it into categories (Anderson \& Burns, 1989). The essential matter of such an analysis technique is to search for meaning rather than an amount of words (Miles \& Huberman, 1994); to 'quickly find, pull out, and cluster the segments relating to a particular research question, hypothesis, construct, or theme' (Miles \& Huberman, 1994, p.57). The 'units that cohered' and linked with a common topic or theme, were marked, broken into sub-topics and clustered under a common topic or theme (Miles \& Huberman, 1994, p.57). When the data were a text or words, the researcher categorized these to make sense of the data. Anderson and Burns (1989) suggest that 'when words are the data, the general data analytic strategy is to organize the data into categories representing characteristics, patterns, or themes of the phenomenon and then to illustrate and support the categories with quotes, vignettes, anecdotes, field notes, or narratives' ( p.207). Categorizing gathers themes or concepts related to the same meaning (Lincoln \& Guba, 1985; Miles \& Huberman, 1994). In this analysis, similar issues were categorized under tentative headings by continual reference to the documents until all the data were realistically, described and fitted in themes. The researcher confirmed the elements of quality teaching as identified by the MOE, the NSWQT Model as a holistic and comprehensive description of quality teaching. This technique helped the researcher to answer the questions: How is quality teaching described in Jordan? How is quality teaching described in the NSWQT Model?

\subsection{Research Questions}

In order to achieve this overarching aim and the objectives outlined above, the study was guided by the following research questions:

1. How is quality teaching described officially in Jordan?

2. How is quality teaching described officially in NSWQT Model?

3. And what are the areas of similarities and differences?

\section{Results}

\subsection{The Jordanian MOE's Articulation of Quality Teaching}

In answering the first research question; how is quality teaching described officially in Jordan?

From the MOE's perspective, the following principles of teaching and learning reflect current best educational practices and take into consideration psychological, environmental, developmental and cognitive factors that can affect the student's ability to learn (Ministry of Education, 2002, 2003a, 2003b, 2004b, 2006a).

\subsubsection{Planning Based on Outcomes}

The present curriculum in Jordan provides teachers with detailed 'units' which outline objectives and teaching methods in a very structured way. When teachers use an outcomes-based curriculum, they do not usually begin their planning with instructional strategies or learning activities (Ministry of Education, 2003b, 2006a). According to the MOE, they start with the learning outcomes because the outcomes are most central to student learning (Ministry of Education, 2003b, 2006a).

\subsubsection{Quality Teaching and Learning Leads to Deep Understanding}

Because learning is not passive, students are supposed to actively participate in learning. Quality learning tasks have a clear purpose and require students to create knowledge from new experiences that make connections to their prior 
knowledge (Jaradat et al., 1983; Ministry of Education, 2002, 2003b, 2006a).

\subsubsection{Different Learning Needs of Students can be Met by Using a Variety of Teaching Methods}

According to the MOE, a variety of teaching methods is required to address different learning approaches and to allow students to benefit from exposure to their preferred and non-preferred learning styles (Ministry of Education, 2003b, 2006a).

\subsubsection{Student-Centered Activities Enable Students to Achieve and Apply Their Learning to Life}

According to the MOE, a curriculum or classroom that is learner-centered allows consideration to be given to individual students as needed. Teachers do not judge their own success exclusively by whether they have presented all the subject material. They focus on maximizing learning for their students and following the interests and abilities of the students (Ministry of Education, 2003b, 2006 a).

\subsubsection{Significance of Teaching and Learning}

Real-life activities are those that relate to the world of the student outside of school. The use of real-life activities motivates students to learn, helps to illustrate new concepts, and helps students' knowledge. Lessons that involve topics of interest help students to make connections to what they already know and to develop new concepts with connections to the world outside of the school (Jaradat et al., 1983; Ministry of Education, 2003a, 2003b, 2006a).

\subsubsection{Teaching and Learning Strategies that Meet Quality Teaching Practices}

The MOE deigned a range of strategies for teachers to choose from to achieve the desired learning, but the teaching and learning strategies need to be those with which the teachers are comfortable. It is important that a teaching strategy is selected with an underlying rationale. For example, for a teacher to say: 'Today, we're going to do group work', they have to know why working in groups is the best way to achieve a particular knowledge. The teaching strategies included are grouped as: direct instruction, problem solving and investigation, group learning, and activity-based learning (Ministry of Education, 2003b, 2006a). In the following section, the researcher illustrates one teaching strategy that is mentioned in the MOE' Framework for Curriculum and Assessment.

\subsubsection{Learning Strategy: Using Critical Thinking}

Critical thinking is the use of analysis, evaluation and reflection. It requires creativity and independence. Critical thinking involves: metacognition, visual organizers and analysis (Ministry of Education, 2003b, 2006a).

\subsubsection{Teaching and Learning Environment}

Jordan's new curriculum provides all students with an opportunity to learn. According to the MOE, student learning is influenced by a number of factors, including the student's learning needs, gender, geographical location, and social background. Quality teachers understand the importance of creating classrooms that are equitable and safe for all students and accommodate a diversity of student needs (Ministry of Education, 2003b, 2006a). The following sections will describe the desired elements of the quality learning environment from the MOE's perspective.

\subsubsection{Equity and Safety}

Successful classrooms do more than provide students with basic competencies. They promote Arabic and Islamic values, beliefs and traditions, and foster positive social development. It is important that the curriculum in Jordan reflects the wide range of behaviors and attitudes available to all citizens (Jaradat et al., 1983; Ministry of Education, 2002, 2003b, 2004b, 2006a).

\subsubsection{Accommodating Student's Needs}

According to the MOE, quality teachers should also take into account those students who have been identified with specific learning disabilities, or who are gifted learners. Quality teachers choose instructional strategies and learning resources that accommodate the needs of all their students, using different strategies to assist them to meet these needs (Jaradat et al., 1983; Ministry of Education, 1996, 2003b, 2006a).

\subsubsection{Use Information and Communication Technology}

Teachers preparing students for the knowledge economy keep pace with cutting edge technologies and integrate this technology into their classrooms as individual and group learning tools. The effectiveness of technologies is evaluated and refinements are made for the best use of ICT for supporting teachers' work and student learning (Ministry of Education, 2002, 2003b, 2006a).

\subsubsection{Assessment and Evaluation of Learner Outcomes}

Assessment is an on-going process aimed at improving both student learning and the instruction provided by teachers. Quality assessment builds skills on self-assessment and reflection both for the student and for the teacher. According to 
the MOE, a good system of assessment, evaluation and reporting should be based on clearly-stated student outcomes (Jaradat et al., 1983; Ministry of Education, 2002, 2003b, 2006a).

\subsection{The NSW Model Articulation of Quality Teaching}

In answering the second research question; how is quality teaching described officially in NSWQT Model?

The model describes quality teaching pointedly as pedagogical practices that consist observably of eighteen elements clustered around three main dimensions. These broad dimensions were termed intellectual quality, quality learning environment, and significance.

\subsubsection{Intellectual Quality}

According to the NSWQT Model, pedagogy should focus on key concepts, ideas, and skills for productive construction of knowledge and should keep students operating at a high rate of intellectual function (NSW Department of Education and Training, 2003b, 2003c). In the following section, this dimension's six elements will be explained.

\subsubsection{Deep Knowledge}

Deep knowledge, according to the model, means that the teacher should give their students the opportunity to understand the central concepts of a particular subject or topic and link these concepts coherently with each other (Killen, 2005; NSW Department of Education and Training, 2003a, 2003b, 2003c; University of Queensland, 2001).

\subsubsection{Deep Understanding}

As stated in the NSWQT Model, deep understanding not only means acquiring knowledge, but having a complex understanding of a collection of ideas or concepts associated with a specific subject. Students who have deep understanding are able to solve problems, and explain and draw inferences and conclusions about the topic under consideration. Deep understanding allows students to demonstrate and/or control an argument based on specific concepts or ideas (Killen, 2005; NSW Department of Education and Training, 2003b, 2003c; University of Queensland, 2001).

\subsubsection{Problematic Knowledge}

According to the NSWQT Model, problematic knowledge is taught and presented in the form of open questions and/or problems needing solutions. The teacher should present the knowledge in an open way so students can find the forms of contestation surrounding the bodies of knowledge and acknowledge the existence of alternatives (Killen, 2005; Newmann et al., 1996; NSW Department of Education and Training, 2003a, 2003c; University of Queensland, 2001).

\subsubsection{Higher-Order Thinking}

As outlined in the NSWQT Model, higher-order thinking means that students are involved in learning that stimulates various thinking processes. This process allows students to explain, synthesize, generalize, hypothesize and draw conclusions or construct an interpretation based on specified information (Killen, 2005; NSW Department of Education and Training, 2003c; University of Queensland, 2001).

\subsubsection{Metalanguage}

According to the model, teachers should use the correct language when presenting specific ideas or information to acknowledge their understanding that certain language (terms and forms) is appropriate for certain areas of study and in certain situations. Teachers and students should talk about the use in particular circumstances of specific words, phrases, genres, images and symbols (Killen, 2005; NSW Department of Education, 2003; NSW Department of Education and Training, 2003c; University of Queensland, 2001)

\subsubsection{Substantive Communication}

The NSWQT Model explains that substantive communication is about the quality of the conversation or interaction between teachers and students. Quality teaching shifts these interactions from being teacher-centered to being student-centered (Newmann \& Associates, 1996; Newmann et al., 1996; NSW Department of Education, 2003). The role of the teacher becomes to encourage a sustainable, reciprocal and reasonably egalitarian interaction between teacher and students and amongst students (Killen, 2005; NSW Department of Education and Training, 2003a, 2003b, 2003c; University of Queensland, 2001).

\subsubsection{Quality Learning Environment}

A quality learning environment is one where successful pedagogical practice takes place in a suitable environment. This dimension declares that its six elements need to work in concert to create a sustainable learning environment. These elements are elaborated below. 


\subsubsection{Explicit Quality Criteria}

Students need to understand the process by which the teacher will judge the quality of their work to achieve required outcomes. Explicit quality criteria are used as a reference point for the teacher and students' learning and for checking progress. According to the model, the criteria should be clear, specific and be explained to students (Killen, 2005; NSW Department of Education, 2003; NSW Department of Education and Training, 2003c; University of Queensland, 2001).

\subsubsection{Engagement}

Engagement, at its simplest level, means students staying on-task at all times. More broadly, it means observable evidence of enthusiastic and interested students who take their work seriously, who show initiative in raising questions, are involved in group work, who help others, and who actively seek help from their teachers (Killen, 2005; NSW Department of Education, 2003; NSW Department of Education and Training, 2003b, 2003c; University of Queensland, 2001).

\subsubsection{High Expectations}

The NSWQT Model makes it clear that without teachers having high expectations of their students regardless of individual differences, then little else the model proposes can be activated. According to the model, the quality teacher is supposed to set challenging tasks for their students to bring out their strengths, abilities and interests. The quality teacher encourages students to take risks in their learning (Killen, 2005; NSW Department of Education, 2003; NSW Department of Education and Training, 2003c; University of Queensland, 2001).

\subsubsection{Social Support}

The NSWQT Model asks the quality teacher to create a classroom atmosphere of mutual respect amongst all the participants in the teaching-learning process. The teacher should respect all efforts made by the students (Killen, 2005; NSW Department of Education, 2003; NSW Department of Education and Training, 2003b, 2003c; University of Queensland, 2001).

\subsubsection{Students' Self-Regulation}

According to the model, quality teaching occurs in environments where a maximum amount of time is spent on learning rather than time wasted on micro-managing, that is, surveilling, regulating and correcting, students' behavior. This can be achieved by allowing students opportunities to set their own learning goals, take initiatives and regulate their own learning and behavior (Newmann \& Associates, 1996; Killen, 2005; Newmann et al., 1996; NSW Department of Education and Training, 2003b, 2003c; University of Queensland, 2001).

\subsubsection{Student Direction}

According to the NSWQT Model, quality teaching occurs when students feel that they are given sufficient and clear choices, time, pace and criteria with regards to initiating and performing their work. Suitable pacing gives students the opportunity to step back and re-think the direction and achievements of their own work. Entitling students to select how they learn, to identify learning activities, deciding how much time they consume, and by which criteria their work will be assessed, enables teachers to appear to be flexible and providing multiple choices for students to enter and exit their learning activities (Killen, 2005; NSW Department of Education, 2003; NSW Department of Education and Training, 2003c; University of Queensland, 2001).

\subsubsection{Significance}

The third dimension of the NSWQT Model is termed significance or, alternatively, relevance. According to the model, this dimension overall means that quality teachers connect classroom learning with the world outside; that they build on their students' background knowledge; and that they connect ideas or concepts across academic disciplines (Killen, 2005; NSW Department of Education, 2003; NSW Department of Education and Training, 2003c; University of Queensland, 2001). The following six elements break down and explain this dimension in more detail.

\subsubsection{Background Knowledge}

The first element demands that background knowledge be taken into consideration when the teachers interact with their students. Teachers are to make connections between the new and the known. This connection provides the building blocks or the foundation for enhancing the learning process. Students' background knowledge may consist of prior formal learning, personal experiences, family backgrounds, community cultures, popular cultures and understandings of the mass media (Killen, 2005; NSW Department of Education, 2003; NSW Department of Education and Training, 2003c; University of Queensland, 2001).

\subsubsection{Cultural Knowledge}

Teachers should be aware of and sensitive to the diversity of their classroom with regard to ethnicity, gender, religion, 
age, sexuality, language, disability and socioeconomic backgrounds. The quality teacher constructs from the variety of cultural knowledge in their classroom productive factors for enhancing students' learning by using the different cultural backgrounds to create channels and points of interest between themselves and their students and between the students (Killen, 2005; NSW Department of Education and Training, 2003a, 2003c; University of Queensland, 2001).

\subsubsection{Knowledge Integration}

This element means that teachers and students connect different topics, concepts and ideas across different topics or subject areas. From the model's perspective, a quality teacher is able to make their lessons more comprehensive by involving different sorts of knowledge from different areas to enhance the in-school relevance of the students' learning and enhance its relevance to the students' lives beyond the classroom (Killen, 2005; NSW Department of Education and Training, 2003a, 2003c; University of Queensland, 2001).

\subsubsection{Inclusivity}

According to the model, quality teachers avoid discriminating against excluding or devaluing their students. Such teachers encourage their students to ask and answer questions freely, as well as to participate in classroom activities regardless of their social status (Killen, 2005; NSW Department of Education and Training, 2003c; University of Queensland, 2001).

\subsubsection{Connectedness}

Quality teaching, according to the NSWQT Model, is teaching that allows students to raise issues in the classroom from outside the classroom, and to try to find workable solutions and/or answers. Teachers are supposed to address aspects that are valued by students and have meaning for them beyond the teaching context. Students come to the classroom with many expectations and aims related to some aspects of their life and seek explanations and interpretations (Killen, 2005; NSW Department of Education and Training, 2003c; University of Queensland, 2001).

\subsubsection{Narrative}

Narrative, according to the NSWQT Model, means using story telling in the teaching and learning process. Story telling often establishes a better relationship between teacher and students when those students are drawn from some special needs groups: they feel happy, become alert and pay more attention to specific points, because it can remind them and connect them to special events or circumstances in their own lives, consequently making learning easier. Stories can take the form of personal anecdotes, biographies, historical accounts, case studies, literary and cultural texts, as well as role play and dramatic performance. Stories can be presented in numerous ways, including written, spoken, read, viewed or listened (Killen, 2005; NSW Department of Education and Training, 2003a, 2003c; University of Queensland, 2001).

\subsection{Comparison and Contrast}

In answering the third research question; what are the areas of similarities and differences?

The two frameworks, the NSWQT Model and the Jordanian Education Ministry's framework, attempt to introduce best practice into schools. The major differences between the two frameworks are the contexts within which they are expected to operate and the histories from which they were created. On the one hand, the Jordanian framework was developed at a national level to be consistent and generic and to meet national demands and desires for education reform. The reformed education system is intended ultimately to contribute to economic dynamism, social stability during social change and political development. On the other hand, the NSWQT Model was developed at a sub-national (State) level accompanied by less grandiose claims for its contribution to national or State development and ostensibly aimed more at measuring and activating the professional development needs of teachers. The NSWQT Model would appear to be the result of the 'fine-tuning' of a developed education system with a well-trained and mature teaching service, while the Jordanian framework has wider and greater needs to meet in developing the infrastructure and the training needed for, and base-line quality of, their teaching service.

The framework's demands on teachers and consequently students, as reflected in the differing degrees of flexibility and experimentation encouraged by each framework, would necessarily be different in each context. The NSWQT Model focuses in a more intimate and fine-grained way on pedagogical practices and retains some of the hallmarks of progressivism, such as calls for student-centred learning, self-assessment and self-pacing, concerns about self-worth and about the human quality of teacher-student relationships, whereas the Jordanian framework recommends a comprehensive framework for curriculum and assessment to guide teachers' activities, while leaving pedagogical practice largely assumed to be standardized and, one would expect, less progressivist in approach. However, while the Jordanian framework tries to address a desired form for teaching and learning, it is a far less precise framework. A possible reason for this is that the Ministry was required, almost immediately on the basis of international 'persuasion' 
and advice; to develop a new framework to meet what was proposed as an internationally comparable conception of a 'modern' curriculum and quality teaching. Such rapid transition without prior preparation created confusion, hesitation and the conditions for a plethora of competing demands to be advanced by politicians, advisers, administrators and teachers.

The pressure for rapid educational change for national development was placed on Jordan, in part, by its acceptance in 2000 of UNESCO's Dakar Framework that had been adopted by the World Education Forum in Senegal, Africa (UNESCO, 2000). This framework reaffirmed the view of education outlined by the World Declaration on Education for All developed in Jomtien, Thailand, in 1990. The Dakar Framework built on the results of the World Conference on Education in 2000 that assessed what was needed to provide basic education around the world and to evaluate progress towards the Jomtien goals (Tamatea, 2005; UNESCO, 2000). The participating countries, including Jordan, pledged to uphold and work towards the framework's recommendations, goals and targets. Of course, substantial international aid was attached to rapid progression towards implementing these goals. Of the six goals, one was about 'improving all aspects of the quality of education and ensuring excellence of all so that recognized and measurable learning outcomes are achieved by all, especially in literacy, numeracy and essential life skills' (UNESCO, 2000, p.8).

The Jordanian Government committed itself to meeting this and the other five goals. The concern was not only to establish an agreed blueprint for achieving these goals, but also to make sure these goals were implemented as conceived by the Dakar Framework. The main obstacle that Jordan and other countries encountered was the lack of existing groundwork and preparation for fully comprehending and activating these goals. It is understandable that participating countries committed themselves perhaps prematurely to such obligations due to loan conditionality required by aid donors and by the World Bank. A dilemma also lay in the variation and gap between these countries in terms of their levels of preparation, fiscal and economic resources, political stability and commitment to the process. Jordanian education officials rushed to put the new framework of quality education in place in an uncertain atmosphere with little preparation work at a grass-roots' level. In other words, the Jordanian Ministry was advancing but leaving teachers, students, and local administrators behind and at the same time ignoring the social context of the already-existing education and social system. Hence, the Jordanian framework was born and implemented in controversial circumstances, which could impact upon its sustainability.

This is in complete contrast with the NSW system, largely unchanged in its basic operation since the Wyndham reforms of the early 1960s (Barcan, 1988). As well, in this remarkably stable context, the NSWQT Model was developed from predecessors tested over many years and across different countries and Australian States. The NSWQT Model was imposed by the educational authorities, but in a staged manner, accompanied by ongoing research, and in a spirit of compromise with a conception of teacher demands for professional development. Therefore, the NSWQT Model was generated and applied in a more endogenous and organic manner or at least it was to be perceived as such by the NSW education authorities, than the Jordanian framework, which was constructed under the vicissitudes of exogenous pressure and applied in an unapologetically top-down manner. In the following section, the similarities and differences between the two frameworks' descriptions of quality teaching will be teased out, since both still see this as a crucial part of their operation. The comparison and contrast will compare two key indicators: the frameworks' identification of the teacher's role in implementing quality teaching and the student's role in responding to quality teaching.

\subsubsection{The Teacher's Role}

There are similarities between the Jordanian and the NSWQT Model's description of the teacher's role in activating quality teaching. These similarities revolve around the idea that the teacher's role in the teaching-learning process should transit from being teacher-centered to student-centered. This means that the teacher's role should change from the traditional one of didacticism, personal dominance of the classroom, 'spoon feeding' or transmission-style teaching, being the only 'legitimate' source of information, having a strong reliance on verbal direction and instruction, and being the only classroom manager and only source of authority, to undertaking the role of guide and facilitator of student learning, while observing, debating, seeking innovation, acting as critical friend to students and staff, modelling a variety of modes of teaching, and constantly consulting students. In the two new frameworks, the teacher is supposed to provide tasks that foster critical thinking and problem solving. Furthermore, the quality teacher creates a classroom culture of learning with high expectations of all students, while taking into consideration students' prior learning and knowledge. The quality teacher, according to the two new frameworks, would arrange assessment criteria on this basis when both when planning and applying teaching practices. In terms of instructional strategies, the quality teacher is expected to provide opportunities for students to make connections to real life, to other subjects and to prior learning and knowledge. Moreover, the quality teacher, according to the two frameworks, encourages students to be active learners, while the teacher asks questions and provides activities requiring higher order thinking by students. Furthermore, whole class discussions (whether in the form of open discussions, round-robin lectures, brainstorming, and/or question and answer sessions) are seen to be the most effective and efficient ways for activating quality teaching 
processes and leading towards students practicing self- and peer-assessment. The teacher, according to the two frameworks, is to use appropriate language when they communicate with their students. This criterion takes different forms in either framework. For example, in the NSWQT Model it is understood as metalanguage - language ranging over and above immediate discourse, while the Jordanian framework asks teachers to use language that both relates to real life and demonstrates the teacher's mastery of appropriate language. Finally, the two frameworks emphasize that teachers need to recognize that students need social support and both enumerate the techniques applicable to this endeavor.

According to the two frameworks the teacher should prepare teaching and learning environments in which teacher and students interact confidently. For example, both frameworks ask teachers to be facilitator and guide for students learning. Both frameworks requested teachers to maximize students' self-direction and regulation rather than exercising power over them and take away their space and choice in teaching and learning activities.

A major difference between the two frameworks in describing teachers' actions is that the Jordanian framework is more prescriptive and more detailed in presenting what teachers should do from the planning stage up to the assessment stage, and makes explicit what criteria teachers should use and how they should use them. It can be surmised that the Jordanian framework seeks to describe and direct explicitly the desired actions expected by the central authority from teachers, whereas the NSWQT Model is less explicit in directing teachers' activity, especially when we consider the model's first dimension 'intellectual quality'. While it is true that the NSWQT Model is elaborated in a sophisticated way, its lack of explicitness raises the question of exactly towards which teachers in which contexts is it directed? It is meant to help teachers develop professionally, but is this reducible to an exclusive focus on classroom teaching as in the NSWQT Model? If so, then perhaps the model should be more explicit and more applicable to immediate classroom practices. Another difference is that the NSWQT Model gives little direction to the teacher for planning their lessons. Planning is generally regarded to be vital for effective teaching. The Jordanian framework recognizes this by giving considerable detail for aiding teachers in planning their curriculum, whether on a daily or semester-long basis. In terms of assessment, the Jordanian framework gives teachers assessment options and alternatives, while the NSWQT Model is both more nebulous in prescribing assessment types but also seems to limit assessment types to those probably more appropriate for secondary schools rather than primary schools.

In terms of cultural knowledge or social background, the Jordanian framework is insufficiently and inadequately clear as to the need for teachers to acknowledge the existence and impact on learning of cultural knowledge or social background. It provides no guidance as to the cultural or social knowledge that teachers should have nor how they should act or react towards manifestations of different cultures and social backgrounds revealed in the classroom. On the contrary, the NSWQT Model explains this requirement of teachers explicitly and gives teachers some idea of the ways in which they should deal with social diversity in their classrooms. Similarly, the NSWQT Model strongly suggests using narrative as a teaching strategy, while the Jordanian framework does not. Another difference is that the Jordanian framework focuses on classroom management as the main base-line criteria for teacher quality, whereas the NSWQT Model is far less explicit and prescriptive about the need for and ways of implementing classroom management, especially in regards to organizing the physical environment and the classroom's 'look', which the Jordanian framework strongly suggests is the main duty of the teacher.

The NSWQT Model is at pains to encourage the practicalities of producing deep knowledge in the classroom and the form it should take in the instruction process. The Jordanian framework does not address this explicitly. The NSWQT Model gives guidance for constructing problematic knowledge and avoiding presenting knowledge as a fixed body of 'truths'. The Jordanian framework makes no explicit attempt to do this.

\subsubsection{The Student's Role}

The two frameworks have similarities and differences when describing the student's role in the classroom. According to both the Jordanian framework and the NSWQT Model, the student is supposed to be a creative and active participant who debates and discusses, presents ideas freely and boldly, criticizes openly and suggests options, makes difficult decisions, stays committed to the path of increasing their knowledge, and who grows through increased understanding. This is most unlike the traditional role of the student being a passive recipient of information, participating at best in a limited way, and expected to memorize information from textbooks and retain it until exam time. The major assessment effort was for students to recall and regurgitate rote-learnt information in the required way at the required time. The more recent expectation of the student's role lodged within both quality teaching models can be summarized as taking six forms, which, paradoxically for some students or in some cultures, may be experienced as more oppressive and/or more demanding than the traditional rote-regurgitate model. The assumed role is: first, engagement by paying attention and listening carefully to the teacher and following carefully the requirements of the learning activities. Second, showing understanding by asking and answering questions. Third, contributing and participating in the lesson by adding 
information, ideas, opinions and comments. Fourth, demonstrating the skills and attributes of problem solving and high-order thinking accompanied by curiosity and eagerness to acquire new knowledge about problems and issues and, thus, to try enthusiastically different methods of problem solving and thoroughly assess their usefulness. Fifth, willingly co-operating with other students in class to learn from them and to encourage those other students to work as a team, while also being willing to work independently and to take full responsibility for personal activities and products. Finally, the 'new model' student regulates and directs themselves with complete commitment to the completion of all their work with only modest guidance from, but while under continual observation and assessment by, the quality teacher. All these assumptions about the student's role are displayed in the two frameworks of quality teaching.

One contrast between the Jordanian and the NSWQT Model's description of the student's role is that the Jordanian framework claims that the student should acquire ICT and other technological skills, whereas the NSWQT Model does not mention technology explicitly. Furthermore, the Jordanian framework describes one part of the student's role to be acquiring and valuing foreign languages, while the NSWQT Model gives no recognition to the importance of knowing or valuing other languages. On the other hand, the NSWQT Model highlights two elements that it considers to be the crucial orientating core of the quality teaching and learning process: deep knowledge and deep understanding, while the Jordanian framework describes these superficially and does not position them as essential elements in the teaching-learning process.

\section{Conclusion}

Despite the slight differences, on the whole the two frameworks agree on the nature of the student's role in the quality teaching-learning process. This role can be boiled down into two statements of assumptions and procedures: firstly, students possess prior knowledge and need to come to class ready to build on this knowledge in order to apply it in real-life situations as useful members of a predetermined social order. Secondly, to achieve this then students have to be involved physically, intellectually, psychologically, emotionally, and socially, that is, totally, in all the teaching-learning activities, procedures and requirements. From this broadest viewpoint, it could be debated whether these frameworks in total are particularly liberating for students or for the teachers who will be held accountable for the fulfilment of their assumptions and procedures. The two frameworks are relatively similar in terms of what they propose as the main characteristics of the quality teacher. They both attempt to explain the role of the quality teacher in terms of achieving 'high quality' work from and for students. Therefore, the two frameworks articulate the concept of quality teaching on the same manner as they have a constructivist approach orientation.

\section{References}

Alshurfat, S. (2003). The Role of Primary School Teachers in Education Change in Jordan. Unpublished Doctor of Philosophy Thesis, University of Western Sydney, Sydney.

Anderson, L., \& Burns, R. (1989). Research in Classrooms: The Study of Teachers, Teaching and Instruction. New York: Pergamon Press.

Anderson, R. C. (1994). Role of the Reader's Schema in Comprehension. Learning and Memory. In R. Ruddell, M. R. Ruddell \& H. Singer (Eds.), Theoretical Models and Processes of Reading (4th ed., pp. 469-482). Newark: International reading Association.

Anyon, J. (1981). School Knowledge and Social Class. Curriculum Inquiry, 11(1), 3-42. http://dx.doi.org/10.2307/1179509

Barcan, A. (1988). Two Centuries of Education in New South Wales. Sydney: New South Wales University Press.

Barr, R., \& Dreeben, R. (1983). How Schools Work. Chicago: University of Chicago press.

Bascia, N., \& Hargreaves, A. (2000). Teaching and Leading on the Sharp Edge of Change. In N. Bascia \& A. Hargreaves (Eds.), The Sharp Edge of Educational Change: Teaching, Leading, and the Realities of Reform (pp. 3-26). London: Routledge Falmer.

Beane, J. A. (1993). A Middle School Curriculum: From Rhetoric to Reality (2nd ed.). Ohio: National Middle School Association.

Berkeley, G. (1991). Teacher Quality - Why the Fuss? UNICORN, 17 (1), 19-23.

Berlak, H., \& Berlak, A. (1981). Dilemmas of Teaching. London: Methuen.

Bernstein, B. (1971a). Class, Codes and Control: Volume 1, Theoretical Studies Towards a Sociology of Language. London: Routledge and Kegan Paul.

Bernstein, B. (1971b). On the Classification and framing of Educational Knowledge. In M. F. Young (Ed.), Knowledge and Control: New Directions for the Sociology of Education (pp. 47-69). London: Collier-Macmillan. 
Bernstein, B. (1973). Class, Codes and Control: Volume 3, Towards a Theory of Educational Transmissions. London: Routledge and Kegan Paul.

Bernstein, B. (1990). The Structuring of Pedagogic Discourse: Class, Codes and Control (Vol. IV). London: Routledge and Kegan Paul. http://dx.doi.org/10.4324/9780203011263

Biggs, J. B. (Ed.). (1991). Teaching for Learning. Melbourne: Australian Council for Educational Research.

Borich, G. D. (2000). Effective teaching methods (4th ed.). New Jersey: Prentice-Hall,Inc.

Bredekamp, S., \& Rosegrant, T. (1995). Reaching Potentials: Transforming Early Childhood Curriculum and Assessment, Volume 2. Washington: National Association for the Education of Young Children.

Brophy, J., \& Good, T. L. (1986). Teacher Behavior and Student Achievement. In M. Wittrock (Ed.), Handbook of Research on Teaching (3rd ed., pp. 328-375). New York: Macmillan Publishing Company.

Bruner, J. S. (1960). The Process of Education. Cambridge: Harvard University Press.

Bruner, J. S. (1960). The Process of Education. Cambridge: Harvard University Press.

Carr, W. (1989). Introduction. In W. Carr (Ed.), Quality in Teaching (pp. 1-18). London: The Falmer Press.

Castells, M. (2000). The Rise of the Network Society. Oxford: Blackwell Publishers.

Cazden, C. B. (1992). Whole language plus. New York: Teachers College Press

Christie, M. J. (1985). Aboriginal Perspectives on Experience and Learning: The Role of Language in Aboriginal Education. Geelong: Deakin University Press.

Cohen, D., \& Barnes, C. (1993a). Conclusion: A New Pedagogy for Policy? In D. Cohen, M. McLaughlin \& J. Talber (Eds.), Teaching for Understanding: Challenges for Policy and Practice (pp. 240-275). San Francisco: Jossey-Bass Publishers.

Cohen, D., \& Barnes, C. (1993b). Pedagogy and Policy. In D. Cohen, M. McLaughlin \& J. Talbert (Eds.), Teaching for Understanding: Challenges for Policy and Practice (pp. 207-239). San Francisco: Jossey-Bass Publishers.

Connell, R. W. (1993). Schools and Social Justice. Philadelphia: Temple University Press.

Cope, B., \& Kalantzis, M. (1995). The Power of Literacy. London: Falmer Press.

Corrales, J. (1999). The Politics of Education Reform: Bolstering the Supply and Demand; Overcoming Institutional Blocks. Washington DC: World Bank.

Crebbin, W. (2004). Quality Teaching and Learning. New York: Peter Lang.

Darling-Hammond, L. (1997). The Right to Learn: A Blueprint for Creating Schools that Work. San Francisco: Jossey-Bass Publishers.

Darling-Hammond, L. \& Youngs, P. (2002). Defining "Highly Qualified Teachers": What Does "Scientifically-Based Research" Actually Tell Us? Educational Researcher, 31(9), 13-25. http://dx.doi.org/10.3102/0013189X031009013

Dewey, J. (1916). Democracy and Education: An Introduction to the Philosophy of Education. New York: Macmillan Company.

Dewey, J. (1956). The Child and The Curriculum: and, the school and Society. Chicago: University of Chicago Press.

Downey, C., Frase, L., \& Peters, J. (1994). The Quality Education Challenge (Vol. 1). California: Corwin Press, INC.

Doyle, W. (1992). Curriculum and Pedagogy. In P. W. Jackson (Ed.), Handbook of Research on Curriculum (pp. 486-512). New York: Macmillan.

Driscoll, M. P. (2005). Psychology of Learning for Instruction (3rd ed.). Boston: Pearson.

Egan, K. (1988). Teaching as Story Telling: An Alternative Approach to Teaching and the Curriculum. Chicago: Routledge.

Egan, K. (1997). The Educated Mind. Chicago: University Of Chicago Press. http://dx.doi.org/10.7208/chicago/9780226190402.001.0001

Fenstermacher, G. D., \& Richardson, V. (2005). On Making Determinations of Quality in Teaching. Teacher College Record, 107 (1), 186-213. http://dx.doi.org/10.1111/j.1467-9620.2005.00462.x

Freebody, P., Ludwig, C., \& Gunn, S. (1995). Everyday Literacy Practices In and Out of Schools in Low Socioeconomic Urban Communities. Canberra: Department of Employment, Education and Training.

Ginott, H. (1971). Teacher and Child. New York: Macmillan. 
Glasser, W. (1986). Control Theory in the Classroom. New York: Harper and Row.

Glasser, W. (1990). The Quality School: Managing Students Without Coercion. New York: Harper Perennial.

Good, T. L., \& Brophy, J. E. (2000). Looking in Classrooms (8th ed.). Sydney: Longman.

Groundwater-Smith, S., Cusworth, R., \& Dobbins, R. (1998). Teaching Challenges and Dilemmas. Sydney: Harcourt Brace.

Groundwater-Smith, S., Ewing, R., \& Cornu, R. (2003). Teaching: Challenges and Dilemmas (2nd ed.). Southbank, Vic: Thomson.

Hargreaves, A. (1994). Changing Teachers, Changing Times: Teachers' Work and Culture in the Postmodern Age. London: Cassel.

Hargreaves, A. (1996). Revising Voice. Education Research, 25(1), 12-19. http://dx.doi.org/10.3102/0013189X025001012

Hargreaves, A. (2003). Teaching in the Knowledge Society: Education in the Age of Insecurity. New York: Teachers College Press.

Hooks, B. (1994). Teaching to Transgress: Education as the Practice of Freedom. New York: Routledge.

Hughes, P. (1988). Quality in Education: A Moving Target. In P. Hughes (Ed.), The Challenge of Identifying and Marketing Quality in Education (pp. 7-10). Sydney: Ashton Scholastic.

Hymes, D. (1996). Ethnography, Linguistics, Narrative Inequality: Toward an Understanding of Voice. London: Taylor and Francis.

Jaradat, I., Obedat, S., Abugazalah, H., \& Abdullatef, K. (1983). Effective Instruction (in Arabic). Amman: Educational Library.

Killen, R. (2003). Effective Teaching Strategies: Lesson from Research and Practice (3rd ed.). Melbourne: Thomson.

Killen, R. (2005). Programming and Assessment for Quality in Teaching and Learning. Southbank, Vic: Thomson.

Lawton, D. (1988). The International Debate on Education: Searching for Quality. In P. Hughes (Ed.), The Challenge of Identifying and Marketing Quality in Education (pp. 13-27). Sydney: Ashton Scholastic.

Lemke, J. (1990). Talking Science: Language Learning and Values. Norwood, New Jersey: Ablex.

Lincoln, Y. \& Guba, E. (1985). Naturalistic Inquiry. New Delhi: Sage Publications.

Luke, A. (1988). Literacy, Textbooks and Ideology. London: Falmer Press.

Massaad, M., Al-Rehanee, S., Ewedat, A., Al-Najar, H., Al-Shaikh, O., Jarwan, F., Naseer, Y., Abu-Alsameed, H., Al-Fra, S., Hashesho, N., Al-Momani, G., Abu-Alshaiq, M., Hananda, A., \& Jaradat, T. (1999). The Jordanian School and the Challenges of Twenty First Century (in Arabic). Amman: Abdul Hameed Shoman Foundation.

Maxwell, T., \& Ninnes, P. (Eds.). (2000b). The Context of Teaching (2nd ed.). Armidale: Kardoorair Press.

McLaughlin, M., \& Talbert, J. (1993). Introduction: New Visions of Teaching. In D. Cohen, M. McLaughlin \& J. Talbert (Eds.), Teaching for Understanding: Challenges for Policy and Practice (pp. 1-10). San Francisco: Jossey-Bass Publishers.

Miles, M. B., \& Huberman, A. M. (1994). Qualitative Data Analysis: An Expanded Sourcebook (2nd ed.). Thousand Oaks, CA: Sage Publications.

Ministry of Education. (2002). Towards a Vision for a New Education System: Vision Forum for the Future of Education in Jordan. Amman, Jordan: Ministry of Education.

Ministry of Education. (2003a). Education Reform for Knowledge Economy. Amman: Ministry of Education.

Ministry of Education. (2003b). General Framework: Curriculum and Assessment (Draft).Unpublished manuscript, Amman.

Ministry of Education. (2004b). The Development of Education: National Report of the Hashemite Kingdom of Jordan. Amman, Jordan: Ministry of Education.

Ministry of Education. (2006a). General Framework: Curriculum and Assessment (in Arabic). Amman, Jordan: Ministry of Education.

Murphy, P. K., Delli, L. A., \& Edwards, M. (2004). The Good Teacher and Good Teaching: Comparing Beliefs of Second-Grade Students, Preservice Teachers, and Inservice Teachers. The Journal of Experimental Education, 72 
(2), 69-92. http://dx.doi.org/10.3200/JEXE.72.2.69-92

Newman, D., Griffin, P., \& Cole, M. (1990). The Construction Zone. Cambridge: Cambridge University Press.

Newmann, F. (1989). Student Engagement and High School Reform. Educational Leadership, 46 (5), 34-36.

Newmann, F. (1991). Classroom Thoughtfulness and Students' Higher Order Thinking: Common Indicators and Diverse Social Studies Courses. Theory and Research in Social Education, 19 (4), 410-433. http://dx.doi.org/10.1080/00933104.1991.10505649

Newmann, F. (1996). Authentic Achievement: Restructuring Schools for Intellectual Quality. San Francisco: Jossey-Bass Publishers.

Newmann, F., Marks, H., \& Gamoran, A. (1996). Authentic Pedagogy and Student Performance. American Journal of Education, 104 (August), 280-312. http://dx.doi.org/10.1086/444136

NSW Department of Education and Training. (2003a). Quality Teaching in New South Wales Public Schools: A Classroom Practice Guide. Sydney: NSW Department of Education and Training.

NSW Department of Education and Training. (2003b). Quality Teaching in New South Wales Public Schools: Continuing the Discussion About Classroom Practice. Sydney: NSW Department of Education and Training.

NSW Department of Education and Training. (2003c). Quality Teaching in New South Wales Public Schools: Discussion Paper. Sydney: NSW Department of Education and Training.

NSW Department of Education. (2003). Quality Teaching in New South Wales Public Schools: An Annotated Bibliography. Sydney: NSW Department of Education and Training.

Oakes, J., Gamoran, A., \& Page, R. N. (1992). Curriculum Differentiation: Opportunities, Outcomes, and Meanings. In P. W. Jackson (Ed.), Handbook of Research on Curriculum (pp. 570-608). New York: Macmillan.

Organisation for Economic Cooperation and Development. (1989). Schools and Quality: An International Report. Paris: Organisation for Economic Cooperation and Development.

Organisation for Economic Cooperation and Development. (1994). Quality in Teaching. Paris: Organisation for Economic Cooperation and Development.

Paterson, D. (2000). Teaching in Inclusive Classrooms in Secondary Schools: A Study of Teachers' Inflight Thinking. Unpublished Doctor of Philosophy Thesis, University of Alberta, Alberta.

Shulman, L. (1987). Knowledge and Teaching: Foundations of the New Reform. Harvard Education Review, 57 (1), $1-22$.

Talbert, J., \& McLaughlin, M. (1993). Understanding Teaching in Context. In D. Cohen, M. McLaughlin \& J. Talbert (Eds.), Teaching for Understanding: Challenges for Policy and Practice (pp. 167-206). San Francisco: Jossey-Bass Publishers.

Tamatea, L. (2005). The Dakar Framework: Constructing and Deconstructing the Global Neo-Liberal Matrix. Globalisation, Societies and Education, 3 (3), 311-334. http://dx.doi.org/10.1080/14767720500166993

Thomas, G., Walker, D., \& Webb, J. (1998). The Making of the Inclusive School. London: Routledge.

UNESCO. (2000, 26-28 April). The Dakar Framework for Action: Education for All - Meeting our Collective Needs. Paper presented at the World Education Forum, Dakar, Senegal.

University of Queensland. (2001). The Queensland School Reform Longitudinal Study: Supplementary Material. Brisbane: Education Queensland.

Wang, M., \& Walberg, H. (1991). Teaching and Educational Effectiveness: Research Synthesis and Consensus from the Field. In H. Waxman \& H. Walberg (Eds.), Effective Teaching: Current Research (pp. 81-104). Berkeley: McCutchan Publishing Corporation.

Westage, D., \& Edwards, A. (1986). Classroom Discourse. London: Falmer Press.

Williams, T. (1988). How Will You Identify the Quality Achievements? In P. Hughes (Ed.), The Challenge of Identifying and Marketing Quality in Education (pp. 113 -122). Sydney: Ashton Scholastic.

Willms, J. (2000). Student Engagement at School: A Sense of Belonging and Participation: Results From PISA 2000. Paris: OECD.

\section{(c) EY}

This work is licensed under a Creative Commons Attribution 3.0 License. 